\title{
Quality Prediction and Control of Reducing Pipe Based on EOS-ELM-RPLS Mathematics Modeling Method
}

\author{
Dong Xiao, ${ }^{1}$ Jichun Wang, ${ }^{1}$ and Huixin Tian ${ }^{2}$ \\ ${ }^{1}$ State Key Laboratory of Synthetical Automation for Process Industries, Northeastern University, Shenyang 110004, China \\ ${ }^{2}$ Electrical Engineering and Automation Department, Tianjin Polytechnic University, Tianjin 300387, China \\ Correspondence should be addressed to Dong Xiao; xiaodong@ise.neu.edu.cn
}

Received 27 December 2013; Accepted 12 February 2014; Published 20 March 2014

Academic Editor: Nachamada Blamah

Copyright (C) 2014 Dong Xiao et al. This is an open access article distributed under the Creative Commons Attribution License, which permits unrestricted use, distribution, and reproduction in any medium, provided the original work is properly cited.

\begin{abstract}
The inspection of inhomogeneous transverse and longitudinal wall thicknesses, which determines the quality of reducing pipe during the production of seamless steel reducing pipe, is lags and difficult to establish its mechanism model. Aiming at the problems, we proposed the quality prediction model of reducing pipe based on EOS-ELM-RPLS algorithm, which taking into account the production characteristics of its time-varying, nonlinearity, rapid intermission, and data echelon distribution. Key contents such as analysis of data time interval, solving of mean value, establishment of regression model, and model online prediction were introduced and the established prediction model was used in the quality prediction and iteration control of reducing pipe. It is shown through experiment and simulation that the prediction and iteration control method based on EOS-ELM-RPLS model can effectively improve the quality of steel reducing pipe, and, moreover, its maintenance cost was low and it has good characteristics of real time, reliability, and high accuracy.
\end{abstract}

\section{Introduction}

As seamless tubes are widely used in various fields such as automobile, aviation, petroleum, chemical industry, architecture, boiler, and military industry and are playing a very important role in national economy, the seamless tubes are called industrial blood vessels. With the rapid development of economy, the service fields of seamless tube expand ceaselessly and the requirements for product quality also become more and more urgent and higher. The working procedure of seamless steel pipe consists of piercing, tube rolling, and tube reducing. Due to the restriction of mandril rigidity during piercing and tube rolling, it is difficult to obtain the seamless steel pipe whose diameter is below $70 \mathrm{~mm}$ on tube rolling train. Also, even a small-sized seamless steel pipe hot rolled whose diameter is greater than $70 \mathrm{~mm}$ is not expected to be produced by rolling a small tubular billet because this will decrease the train productivity by leaps and bounds. Therefore, it is reasonable to produce steel pipe with a small diameter using reducing mode. Owing to the use of reducing process, people can use tubular billet with a large diameter for piercing and rolling, larger reducing can be achieved in reducing mill train, and hence long pipe with a small diameter is obtained, which is an effective technical measure in increasing the output, expanding product variety, and reducing consumption. Various countries throughout the world tend to adopt continuous rolling process with high efficiency in steel pipe extending working procedure to produce shell with single specification and alter technical process in reducing working procedure to obtain finished pipes in different specifications.

Since tension reducing mill is the last forming equipment in steel pipe hot rolling production and has big influence on the steel pipe quality, the deviation of wall thickness is an important index in deciding the steel pipe quality. However, as the mechanism model for pipe reducing process is limited and the quality monitoring of the pipe is accomplished by the periodical spot-check of technical personnel, the inspection results lag severely. Thus, it is significant in theory and economy to establish the wall thickness prediction model of steel pipe reducing with a sufficient accuracy. Macrea and Cepisca [1], Bayoumi [2], and Zhang et al. [3] established a mechanism model of reducing mill and analyzed the indexes such as tension, velocity, and wall thickness during reducing 
process but there are too many restraints in his model, and his model is appropriate for individual production train and is bad in versatility. Yu et al. [4, 5], Yi et al. [6], Xu and Du [7], Du et al. [8], Yuan et al. [9], and Shi et al. [10] utilized finite element software to simulate the reducing process of seamless steel pipe, performed prediction for the key indexes such as dimensions and wall thickness of reduced steel pipe. Their works were used for setting the technical parameters in reducing production and achieved a certain practical effect. However, due to the restriction of finite element software, its precision of prediction is not high and is more appropriate for the development of products with new specifications instead of the online real time control of steel pipe. Shuang et al. [11] analyzed different processes of incoming material and the pipe thicknesses and lengths during tension-reduction process in an iron and steel company using neural network BP algorithm but they only considered the influence of incoming shell dimension and entrance temperature, and did not considered the effect of reducing production process on product quality.

It takes dozen of seconds to produce a piece of steel pipe using reduction. Thus it can be seen that the seamless steel pipe reducing production process is a typical rapid intermittent one. Plentiful production data on site provide convenience for our use of soft measurement method during intermittent production process. Data from reducing production process take on echelon distribution. In the meantime, as the product specifications often change, it is very difficult to guarantee the same adjustment of stand this time as that of last time for products with the same specification. This will lead to the occurrence of a certain time-varying in model. These problems result in low precision of modeling established by traditional intermittent process modeling method such as multiway PLS. The modeling is difficult to be used in prediction and control of field products. Aiming at the production process characteristics such as time-varying, nonlinearity, rapid intermission, and data echelon distribution, we proposed to use EOS-ELM-RPLS (ensemble of online sequential-extreme learning machine-recursive partial least square) algorithm to establish the quality prediction model for reducing production. Under the circumstance of ensuring high precision, the model has high flexibility and adaptability and can be well used in the prediction and control of product quality on production site.

\section{Time Interval Division of Reducing Production Process and Analysis of Quality Influential Factors of Reducing Pipe}

2.1. Time Interval Division of Reducing Production Process. In order to establish accurately the quality prediction model of reducing pipe, one should firstly analyze the factors influencing the quality of reducing pipe to prevent incomplete information and existed redundancy during modeling from decreasing the precision of model. It is known through the analysis of process characteristic that the effect of various independent variables on the quality of reducing pipe during different time intervals is different. Part of variables only

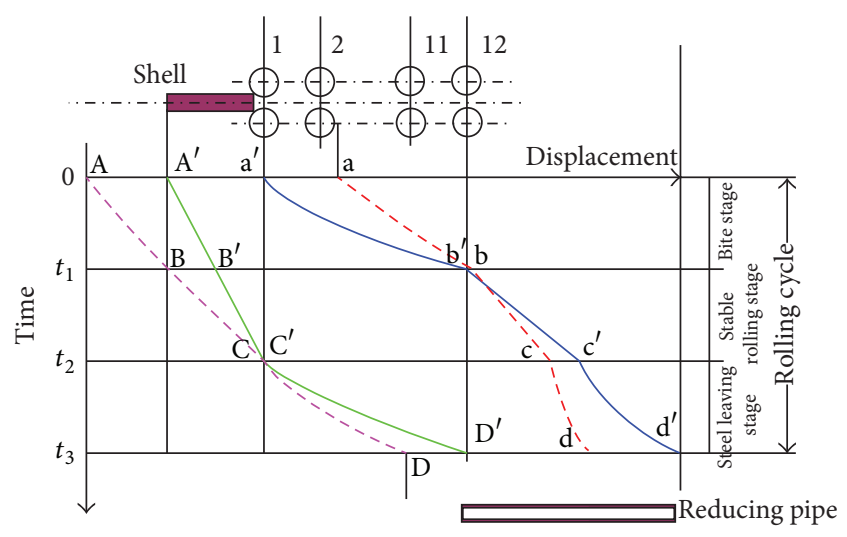

FIGURE 1: The relation between time and displacement of reducing tube.

exist in some time intervals and can be treated as factors observing quality of reducing pipe, whereas another part of variables run through entire production process and has large influence on the quality of reducing pipe.

Steel pipe reducing process is substantially a hollow body sinking continuous rolling process. As shown in Figure 1, three stages can be divided from the head of steel pipe to entrance of the first stand until away from the last stand in the tail.

(1) Bite stage: bite stage means the stage from pipe head to enter the first stand till the pipe head to enter the last stand. As shown in Figure 1, begin when the steel pipe head enters the first rolling mill and end when the steel pipe head encounters the 12th rolling mill. Steel pipe head moves from point $\mathrm{a}^{\prime}$ to point $\mathrm{b}^{\prime}$, and steel pipe tail moves from point $\mathrm{A}^{\prime}$ to point $\mathrm{B}^{\prime}$ when the pipe head gradually passes various stands and its speed increases with increasing coefficient of extension. At this stage, the influence variables of various rolling mills increase according to advance stepping of steel pipe.

(2) Stable rolling stage: from pipe head to enter the last stand till the pipe tail still not to be away from the first stand, when whole mill train rolls the same piece of steel pipe, and rolling load and speed are all stable, called stable rolling stage. As shown in Figure 1, begin when the steel pipe head meets the 12th rolling mill, and end when the steel pipe tail encounters the 1st rolling mill. Steel pipe head moves from point $b^{\prime}$ to point $c^{\prime}$, and steel pipe tail moves from point $B^{\prime}$ to point $C^{\prime}$. At this stage, the variables of various rolling mills have influence on steel pipe.

(3) Steel leaving stage: from pipe tail away from the 1st stand till away from the last stand. As shown in Figure 1, begin when the steel pipe tail meets the 1 sh rolling mill, and end when the steel pipe tail encounters the 12th rolling mill. Steel pipe head moves from point $c^{\prime}$ to point $d^{\prime}$, and steel pipe tail moves from point $C^{\prime}$ to point $D^{\prime}$. At this stage, the number of stands taking part in rolling this piece of steel pipe at 
the same time decreases gradually until single stand rolling in the last stand, and whole piece of steel pipe finishes rolling. Then the steel pipe is expelled out of the stand. At this stage, the influence variables of various rolling mills decrease according to advance stepping of steel pipe.

\subsection{Analysis of Quality Influential Factors of Reducing Pipe}

2.2.1. Influence of Shell Heating Temperature. The heating temperature of shell will bring about the variation of metallic resistance to deformation and result in the variation in rolling force and average tension coefficient. The higher the heating temperature of shell is, the lower the metallic resistance to deformation is, the smaller the rolling force is, and the smaller the external diameter undulation of steel pipe is. In addition, the heating temperature of shell is a function of steel pipe diameter and obvious positive correlation exists between the heating temperature and the diameter. The higher the heating temperature of shell is, the bigger the thermal external diameter of steel pipe is after metal is subjected to thermal expansion.

2.2.2. Influence of Rolling Speed. It is generally recognized that friction factor plays a role concerning the effect of rolling speed on metallic transverse inhomogeneous deformation during reduction of shell. The lower the rolling speed is, the larger the friction force is, and hence the more favorable it reduces the in-homogeneity of steel pipe wall thickness.

2.2.3. Influence of Shell Quality. When the shell reduces, it is difficult to control its wall thickness because its inner surface is not supported by mandril and the pipe wall of the shell will be in a free varying state with changing rolling process condition. Moreover, the in-homogeneity wall thickness of the shell will be inherited to the finished steel pipe after reduction. Therefore, it is an important condition to improve the wall thickness homogeneity of shell in order to guarantee the wall thickness precision of finished steel pipe.

2.2.4. Influence of Tension. When tension reducing mill is used for the reducing of shell, due to the existence of tension, the diameter of shell decreases while the wall thickness thins. Under stable tension condition, metallic transverse deformation is small, which is favorable for the improvement of the precision of steel pipe wall thickness. However, tension cannot be established or tension undulation occurs among stands when the head of pierced pipe enters in turn various reducing roll stands and the tail end of shell leaves in turn various reducing roll stands. Thus the in-homogeneity of longitudinal wall thickness in the steel pipe certainly will occur.

2.3. Determination of Input and Output Variables. The output of quality prediction model is the quality of reducing pipe. The quantification index of judging the quality of reducing pipe is the transverse and longitudinal wall thickness. Transverse wall thickness in-homogeneity is the ratio of maximum wall thickness deviation to nominal wall thickness. Its calculation formula is shown as follows:

$$
\Delta S \%=\frac{\delta_{\max }-\delta_{\min }}{\delta_{\mathrm{HOM}}} \times 100,
$$

where $\Delta S \%$ : relative in-homogeneity of transverse wall thickness; $\delta_{\max }$ : maximum wall thickness of steel pipe; $\delta_{\min }$ : minimum wall thickness of steel pipe; $\delta_{\mathrm{HOM}}$ : nominal wall thickness of steel pipe.

The size of in-homogeneity of longitudinal wall thickness in steel pipe is determined by the difference between the mean value of rough pipe front-end wall thickness and the mean value of rear-end wall thickness. Its calculation formula is shown as follows:

$$
\Delta S_{\mathrm{np}}=\frac{\sum_{i=1}^{n} \delta_{\text {nep }}}{n}-\frac{\sum_{i=1}^{n} \delta_{3 \mathrm{an}}}{n},
$$

where $\sum_{i=1}^{n} \delta_{\text {nep }}$ and $\sum_{i=1}^{n} \delta_{3 \text { an }}$ are the sum of measured frontend wall thickness and rear-end wall thickness of steel pipe, respectively; $n$ is the number of measured points at each end [12].

\section{EOS-ELM-RPLS Algorithm}

3.1. Nonlinear PLS. Since linear PLS model cannot describe correctly the nonlinear relation between independent variable $X$ and dependent variable $Y$, nonlinear PLS method is required to solve this issue. Wold et al. extended at the PLS method to nonlinear field $[13,14]$. There are two feasible methods in nonlinear PLS methods: one is to perform array extension for input matrix, introduce some nonlinear terms of original variable, for example, the square term, and then regress the extended input and output matrix using PLS method. If prior knowledge on the relation of original input variable does not exist, this method cannot guide the selection of combined mode and may lead to oversized dimension of input matrix and the difficulties of processing; the other is to reserve the linear external model of PLS method. Internal model is nonlinear.

(1) External relation model:

$$
\begin{aligned}
& X=T P^{T}+E=\sum_{a=1}^{A} t_{a} p_{a}^{T}+E, \\
& Y=U Q^{T}+F=\sum_{a=1}^{A} u_{a} q_{a}^{T}+F,
\end{aligned}
$$

where $A$ is the number of reserved eigenvector, $t_{a}(n \times$ $1)$ and $u_{a}(n \times 1)$ are the score vector of $X$ and $Y$, respectively, $p_{a}(m \times 1)$ and $q_{a}(p \times 1)$ are the load vector of $X$ and $Y$, respectively, $T(n \times A)$ and $U(n \times A)$ are the score matrix of $X$ and $Y$, respectively, $P(m \times A)$ and $Q(p \times A)$ are the load matrix of $X$ and $Y$, respectively, and $E$ and $F$ are the fit residual matrix of $X$ and $Y$, respectively.

(2) Internal relation model:

$$
\widehat{u}_{a}=f\left(t_{a}\right)+\varepsilon,
$$


where $f(\cdot)$ is the nonlinear function and $\varepsilon$ is the residual.

Since neural network has the capability of fitting nonlinearity, during the modeling of batch process, nonlinear multiway PLS method that internal model adopts neural network gains extensive application. As traditional feedforward neural network adopts gradient learning algorithm during training, parameters in network needs iteration and update. Not only does the training time last long but also it easily results in the issues of local minimum and excessive training [15].

3.2. ELM Algorithm. In supervised batch learning, the learning algorithms use a finite number of input-output samples for training $[16,17]$. For $N$ arbitrary distinct samples $\left(x_{i}, t_{i}\right) \in$ $R^{n} \times R^{m}$, where $x_{i}$ is a $n \times 1$ input vector and $t_{i}$ is a $m \times 1$ target vector, if an SLFN (single-hidden layer feedforward neural network $[18,19]$ ) with $\widetilde{N}$ hidden nodes can approximate these $N$ samples with zero error, it then implies that there exists $\beta_{i}$, $a_{i}$, and $b_{i}$ such that

$$
f_{\widetilde{N}}\left(x_{j}\right)=\sum_{i=1}^{\widetilde{N}} \beta_{i} G\left(a_{i}, b_{i}, x_{j}\right)+\varepsilon_{j}=t_{j},
$$

where $j=1, \ldots, N, a_{i}$ and $b_{i}$ are the learning parameters of hidden nodes (weight vector connecting the input node to the hidden node and threshold of the hidden node) which are randomly selected according to the proof given by Huang et al. and $\beta_{i}$ is the weight connecting the $i$ th hidden node to the output node. To avoid overfitting the noise in the data, an error term $\varepsilon_{j}$ is added. $G\left(a_{i}, b_{i}, x\right)$ is the output of the $i$ th hidden node with respect to the input $x$ and $\widetilde{N}$ is the number of hidden nodes which can be determined by trial and error or prior expertise. Then, the equation can be written compactly as

$$
H \beta=T,
$$

where

$$
\begin{aligned}
& H\left(a_{1}, \ldots, a_{\widetilde{N}}, b_{1}, \ldots, b_{\widetilde{N}}, x_{1}, \ldots, x_{N}\right) \\
& =\left[\begin{array}{ccc}
G\left(a_{1}, b_{1}, x_{1}\right) & \cdots & G\left(a_{\widetilde{N}}, b_{\widetilde{N}}, x_{1}\right) \\
\vdots & \ldots & \vdots \\
G\left(a_{1}, b_{1}, x_{N}\right) & \cdots & G\left(a_{\widetilde{N}}, b_{\widetilde{N}}, x_{N}\right)
\end{array}\right]_{N \times \widetilde{N}}, \\
& \beta=\left[\begin{array}{c}
\beta_{1}^{T} \\
\vdots \\
\beta_{\widetilde{N}}^{T}
\end{array}\right]_{\widetilde{N} \times m}, \quad T=\left[\begin{array}{c}
t_{1}^{T} \\
\vdots \\
t_{N}^{T}
\end{array}\right]_{N \times m},
\end{aligned}
$$

where $H$ is called the hidden layer output matrix of the network; the $i$ th column of $H$ is the $i$ th hidden node's output vector with respect to inputs $x_{1}, x_{2}, \ldots, x_{N}$ and the $j$ th row of $H$ is the output vector of the hidden layer with respect to input $x_{j}$. The hidden node parameters $a_{i}$ and $b_{i}$ need not be tuned during training and may simply be assigned with random values. Equation (6) then becomes a linear system and the output weights $\beta$ are estimated as

$$
\tilde{\beta}=H^{+} T
$$

where $\mathrm{H}^{+}$is the Moore-Penrose generalized inverse of the hidden layer output matrix $H$ [20].

3.3. OS-ELM Algorithm. In real applications, the training data may arrive chunk-by-chunk or one-by-one; hence, the batch ELM algorithm has to be modified for this case so as to make it online sequential $[21,22]$.

The output weight matrix $\widehat{\beta}\left(\widehat{\beta}=H^{+} T\right)$ given in (9) is a least-squares solution of (7). Here we consider the case where $\operatorname{rank}(H)=\widetilde{N}$ is the number of hidden nodes. Under this condition, $H^{+}$of (9) is given by

$$
H^{+}=\left(H^{T} H\right)^{-1} H^{T}
$$

If $H^{T} H$ tend to become singular, one can make it nonsingular by choosing smaller network size $\widetilde{N}$ or increasing data number $N$ in the initialization phase of OS-ELM. Substituting (10) to (9), $\widehat{\beta}$ becomes

$$
\widehat{\beta}=\left(H^{T} H\right)^{-1} H^{T} T \text {. }
$$

Equation (11) is called the least-squares solution to $H \beta=$ $T$. Sequential implementation of least-squares solution of (11) results in the OS-ELM.

Given a chunk of initial training set $\aleph_{0}=\left\{\left(x_{i}, t_{i}\right)\right\}_{i=1}^{N_{0}}$ and $N_{0} \geq \widetilde{N}$, if one considers using the batch ELM algorithm, one need to consider the solution of minimizing $\left\|H_{0} \beta-T\right\|$, which is given by $\beta_{0}=K_{0}^{-1} H_{0}^{T} T_{0}$, where $K_{0}=H_{0}^{T} H_{0}$.

Suppose that we have another chunk of data $\aleph_{1}=$ $\left\{\left(x_{i}, t_{i}\right)\right\}_{i=N_{0}+1}^{N_{0}+N_{1}}$, where $N_{1}$ is the number of samples in this chunk. The problem becomes minimizing

$$
\left\|\left[\begin{array}{l}
H_{0} \\
H_{1}
\end{array}\right] \beta-\left[\begin{array}{l}
T_{0} \\
T_{1}
\end{array}\right]\right\|
$$

Considering both $\aleph_{0}$ and $\aleph_{1}$, the output weight $\beta$ becomes

$$
\beta_{1}=K_{1}^{-1}\left[\begin{array}{l}
H_{0} \\
H_{1}
\end{array}\right]^{T}\left[\begin{array}{l}
T_{0} \\
T_{1}
\end{array}\right], \quad \text { where } K_{1}=\left[\begin{array}{l}
H_{0} \\
H_{1}
\end{array}\right]^{T}\left[\begin{array}{l}
H_{0} \\
H_{1}
\end{array}\right]
$$

For sequential learning, we have to express $\beta_{1}$ as a function of $\beta_{0}, K_{1}, H_{1}$, and $T_{1}$ and not a function of the data set $\aleph_{0}$. Now $K_{1}$ can be written as

$$
\begin{gathered}
K_{1}=\left[\begin{array}{ll}
H_{0}^{T} & H_{1}^{T}
\end{array}\right]\left[\begin{array}{l}
H_{0} \\
H_{1}
\end{array}\right]=K_{0}+H_{1}^{T} H_{1} \\
{\left[\begin{array}{l}
H_{0} \\
H_{1}
\end{array}\right]^{T}\left[\begin{array}{l}
T_{0} \\
T_{1}
\end{array}\right]} \\
=H_{0}^{T} T_{0}+H_{1}^{T} H_{1}=K_{0} K_{0}^{-1} H_{0}^{T} T_{0}+H_{1}^{T} T_{1} \\
=K_{0} \beta_{0}+H_{1}^{T} T_{1}=\left(K_{1}-H_{1}^{T} H_{1}\right) \beta_{0}+H_{1}^{T} T_{1} \\
=K_{1} \beta_{0}-H_{1}^{T} H_{1} \beta_{0}+H_{1}^{T} T_{1} .
\end{gathered}
$$


Combining (13) and (15), $\beta_{1}$ is given by

$$
\begin{aligned}
\beta_{1} & =K_{1}^{-1}\left[\begin{array}{l}
H_{0} \\
H_{1}
\end{array}\right]^{T}\left[\begin{array}{l}
T_{0} \\
T_{1}
\end{array}\right]=K_{1}^{-1}\left(K_{1} \beta_{0}-H_{1}^{T} H_{1} \beta_{0}+H_{1}^{T} T_{1}\right) \\
& =\beta_{0}+K_{1}^{-1} H_{1}^{T}\left(T_{1}-H_{1} \beta_{0}\right)
\end{aligned}
$$

where $K_{1}=K_{0}+H_{1}^{T} H_{1}$.

When $(k+1)$ th chunk of data set

$$
\aleph_{k+1}=\left\{\left(x_{i}, t_{i}\right)\right\}_{i=\left(\sum_{j=0}^{k} N_{j}\right)+1}^{\sum_{j=0}^{k+1} N_{j}}
$$

is received, where $k \geq 0$ and $N_{k+1}$ denotes the number of samples in $(k+1)$ th chunk, we have

$$
\begin{aligned}
& K_{k+1}=K_{k}+H_{k+1}^{T} H_{k+1}, \\
& \beta_{k+1}=\beta_{k}+K_{k+1}^{-1} H_{k+1}^{T}\left(T_{k+1}-H_{k+1} \beta_{k}\right) .
\end{aligned}
$$

$K_{k+1}^{-1}$ rather than $K_{k+1}$ is used to compute $\beta_{k+1}$ from $\beta_{k}$ in (18). The update formula for $K_{k+1}^{-1}$ is derived using the Woodbury formula:

$$
\begin{aligned}
K_{k+1}^{-1} & =\left(K_{k}+H_{k+1}^{T} H_{k+1}\right)^{-1} \\
& =K_{k}^{-1}-K_{k}^{-1} H_{k+1}^{T}\left(I+H_{k+1} K_{k}^{-1} H_{k+1}^{T}\right)^{-1} \times H_{k+1} K_{k}^{-1} .
\end{aligned}
$$

Let $P_{k+1}=K_{k+1}^{-1}$, then the equation for updating $\beta_{k+1}$ can be written as

$$
\begin{aligned}
& P_{k+1}=P_{k}-P_{k} H_{k+1}^{T}\left(I+H_{k+1} P_{k} H_{k+1}^{T}\right)^{-1} H_{k+1} P_{k}, \\
& \beta_{k+1}=\beta_{k}+P_{k+1} H_{k+1}^{T}\left(T_{k+1}-H_{k+1} \beta_{k}\right) .
\end{aligned}
$$

Equation (20) gives the recursive formula for $\beta_{k+1}$.

3.4. Ensemble of OS-ELM Algorithm. EOS-ELM consists of many OS-ELM networks with the same number of hidden nodes and the same activation function for each hidden node [23]. It has constructed $P$ OS-ELM networks to form our EOS-ELM. All $P$ OS-ELMs are trained with new data in each incremental step. The input parameters for each OS-ELM network are randomly generated and the output weights are obtained analytically based on the sequential arrived input data. Then we compute the average of the outputs of each OSELM network, which is the final output of the EOS-ELM.

Assume the output of each OS-ELM network is $g^{j}\left(x_{i}\right), j=$ $1,2, \ldots$. . Hence, we have

$$
g\left(x_{i}\right)=\frac{1}{P} \sum_{i=1}^{P} g^{j}\left(x_{i}\right) .
$$

3.5. EOS-ELM-RPLS Modeling Steps. The difference of nonlinear RPLS modeling method based on OS-ELM from linear PLS method is that it uses ELM to establish internal nonlinear model and in the meantime and achieve the update of internal and external models. This method reserves linear external model, extracts through PLS the attributive information of process, eliminates the colinearity of data, reduces the dimension of input variable, then adopts ELM to establish nonlinear internal model between input score vector matrix and output score vector, and raises the nonlinear processing capability of internal model. Thus, EOS-ELM-RPLS method has the advantages of PLS and ELM, that is, the characteristics of robustness and feature extraction of PLS method and quick nonlinear processing capability of ELM as well as the precision accuracy through model real-time update.

The modeling and testing steps of nonlinear RPLS method based on EOS-ELM are as follows.

(1) Assign two standardized data matrices, $X \in R^{n \times m}$ and $Y \in R^{n \times p}$; dynamic nonlinear PLS regression model can be expressed as follows:

$$
\mathbf{X}=\left[\mathbf{x}_{1}, \mathbf{x}_{2}, \ldots, \mathbf{x}_{p}\right] .
$$

(2) Deploy the batch data of batch process, use crossvalidation method to determine the number of latent variable, adopt linear PLS method to calculate the score vector matrices $T$ and $U$, and load vector matrices $P$ and $Q$ for modeling sample $X$ and $Y$ :

$$
\begin{gathered}
X=T P^{T}+E=\sum_{a=1}^{A} t_{a} p_{a}^{T}+E, \\
Y=U Q^{T}+F=\sum_{a=1}^{A} u_{a} q_{a}^{T}+F .
\end{gathered}
$$

(3) Assign the node number of ELM hidden layer and activation function (e.g., sigmoid function), use ELM to establish nonlinear model between internal model $T$ and $U$, and gain $U=f_{\mathrm{ELM}}(T)$, where $f_{\mathrm{ELM}}(\cdot)$ is the nonlinear function indicated by EOS-ELM.

(4) When new batch data $X_{1}, Y_{1}$ are obtained, we perform PLS decompose firstly, and obtain score vector and load vector $T_{1}, U_{1}, P_{1}, Q_{1}$ :

$$
\begin{aligned}
& X_{1}=T_{1} P_{1}^{T}+E, \\
& Y_{1}=U_{1} Q_{1}^{T}+F .
\end{aligned}
$$

According to formula (19), EOS-ELM algorithm is adopted to update output layer weight value and achieve the update of internal model; in the meantime, conduct weighted mean on load matrix of external model and achieve external RPLS update, where $w$ is the weight value factor. Repeat above steps; conduct model update on every batch:

$$
\begin{gathered}
P^{T}=w P^{T}+(1-w) P_{1}^{T}, \\
Q^{T}=w Q^{T}+(1-w) Q_{1}^{T} .
\end{gathered}
$$


TABLE 1: Size table of reducing tube.

\begin{tabular}{|c|c|c|c|c|c|c|}
\hline Ser. number & $\begin{array}{l}\text { External diameter } \\
\text { of shell }\end{array}$ & $\begin{array}{c}\text { Wall thickness of } \\
\text { shell }\end{array}$ & $\begin{array}{l}\text { External diameter } \\
\text { of finished pipe }\end{array}$ & $\begin{array}{l}\text { Wall thickness of } \\
\text { finished pipe }\end{array}$ & $\begin{array}{c}\text { Number of variable } \\
\text { stands }\end{array}$ & $\begin{array}{l}\text { Number of total } \\
\text { stands }\end{array}$ \\
\hline 1 & 152.5 & 4.25 & 42.2 & 3.56 & 18 & 24 \\
\hline 2 & 152.5 & 10.25 & 70 & 10.25 & 12 & 18 \\
\hline 3 & 152.5 & 7.75 & 139.7 & 7.72 & 12 & 16 \\
\hline 4 & 152.5 & 6 & 73.03 & 5.51 & 12 & 12 \\
\hline 5 & 152.5 & 9.75 & 114.3 & 10 & 10 & 16 \\
\hline 6 & 152.5 & 25 & 121 & 25 & 10 & 12 \\
\hline 7 & 152.5 & 6 & 139.7 & 6.2 & 10 & 10 \\
\hline
\end{tabular}

TABLE 2: Variable table for modeling of reducing tube quality.

\begin{tabular}{lcl}
\hline Ser. number & Variable name & Variable meaning \\
\hline 1 & $x_{1}, x_{2}, x_{3}$ & Motor speed, current, and torque of Number 1 reducing mill \\
2 & $x_{4}, x_{5}, x_{6}$ & Motor speed, current, and torque of Number 2 reducing mill \\
3 & $x_{7}, x_{8}, x_{9}$ & Motor speed, current, and torque of Number 3 reducing mill \\
4 & $x_{10}, x_{11}, x_{12}$ & Motor speed, current, and torque of Number 4 reducing mill \\
5 & $x_{13}, x_{14}, x_{15}$ & Motor speed, current, and torque of Number 5 reducing mill \\
6 & $x_{16}, x_{17}, x_{18}$ & Motor speed, current, and torque of Number 6 reducing mill \\
7 & $x_{19}, x_{20}, x_{21}$ & Motor speed, current, and torque of Number 7 reducing mill \\
8 & $x_{22}, x_{23}, x_{24}$ & Motor speed, current, and torque of Number 8 reducing mill \\
9 & $x_{25}, x_{26}, x_{27}$ & Motor speed, current, and torque of Number 9 reducing mill \\
10 & $x_{28}, x_{29}, x_{30}$ & Motor speed, current, and torque of Number 10 reducing mill \\
11 & $x_{31}, x_{32}, x_{33}$ & Motor speed, current, and torque of Number 11 reducing mill \\
12 & $x_{34}, x_{35}, x_{36}$ & Motor speed, current, and torque of Number 12 reducing mill \\
13 & $x_{37}$ & The temperature of shell \\
14 & $x_{38}$ & The transverse wall thickness of shell \\
15 & $x_{39}$ & The longitudinal wall thickness of shell \\
\hline
\end{tabular}

(5) Use testing data to check model precision. Conduct PLS decomposition on the testing data $X_{2}$, gain score vector $T_{2}$,

$$
X_{2}=T_{2} P^{T}+E
$$

Introduce $T_{2}$ into EOS-ELM model, gain $U_{2}=$ $f_{\text {EOS-ELM }}\left(T_{2}\right)$, find out model prediction value through $\widehat{Y}=$ $U Q^{T}$.

\section{Modeling and Control of Reducing Pipe Quality}

4.1. Establishment of Quality Prediction Model of Reducing Pipe. As there are many specifications of reducing pipe products, one cannot predict accurately the quality of steel pipe using single model. One must classify data in accordance with the specifications of products. As shown in Table 1, production data were classified into seven categories and seven quality prediction models of reducing pipe were established.
Taking the specification of steel pipe in series Number 4 with the maximum output as an example, detailed information of various input variables using this model is shown in Table 2.

Prior to establishing quality prediction model of reducing pipe, one must preprocess modeling data and conduct batch treatment, time interval division, mean value treatment, and two-dimensional spread on the modeling data. On the basis of obtaining three-dimensional data, one must process the process data into subsections according to different time intervals of production operation. In this work, according to the variation of roll current, one firstly classified the production process of reducing pipe into bite subtime interval, stable rolling subtime interval, and steel leaving subtime interval. Then according to the sequence of roll addition, bite and steel leaving stages were divided in detail. Bite stage was divided into eleven subtime intervals and in the same way, steel leaving stage was divided into eleven subtime intervals. After process variables in various time intervals required by modeling were determined, one took the mean value of each process variable in this time interval. Practical data treatment is shown in Figure 2. 


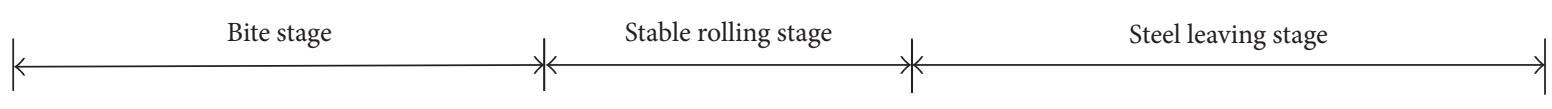

\begin{tabular}{|c|c|c|c|c|c|c|c|c|c|c|c|c|c|c|c|c|c|c|c|c|c|c|}
\hline Number 1 roll $\bar{X}_{1,1}$ & $\bar{X}_{1,2}$ & $\bar{X}_{1,3}$ & $\bar{X}_{1,4}$ & $\bar{X}_{1,5}$ & $\bar{X}_{1,6}$ & $\bar{X}_{1,7}$ & $\bar{X}_{1,8}$ & $\bar{X}_{1,9}$ & $\bar{X}_{1,10}$ & $\bar{X}_{1,11}$ & $\bar{X}_{1,12}$ & & & & & & & & & & & \\
\hline Number 2 roll & $\bar{X}_{2,1}$ & $\bar{X}_{2,2}$ & $\bar{X}_{2,3}$ & $\bar{X}_{2,4}$ & $\bar{X}_{2,5}$ & $\bar{X}_{2,6}$ & $\bar{X}_{2,7}$ & $\bar{X}_{2,8}$ & $\bar{X}_{2,9}$ & $\bar{X}_{2,10}$ & $\bar{X}_{2,11}$ & $\bar{X}_{2,12}$ & & & & & & & & & & \\
\hline Number 3 roll & & $\bar{X}_{3,1}$ & $\bar{X}_{3,2}$ & $\bar{X}_{3,3}$ & $\bar{X}_{3,4}$ & $\bar{X}_{3,5}$ & $\bar{X}_{3,6}$ & $\bar{X}_{3,7}$ & $\bar{X}_{3,8}$ & $\bar{X}_{3,9}$ & $\bar{X}_{3,10}$ & $\bar{X}_{3,11}$ & $\bar{X}_{3,12}$ & & & & & & & & & \\
\hline Number 4 roll & & & $\bar{X}_{4,1}$ & $\bar{X}_{4,2}$ & $\bar{X}_{4,3}$ & $\bar{X}_{4,4}$ & $\bar{X}_{4,5}$ & $\bar{X}_{4,6}$ & $\bar{X}_{4,7}$ & $\bar{X}_{4,8}$ & $\bar{X}_{4,9}$ & $\bar{X}_{4,10}$ & $\bar{X}_{4,11}$ & $\bar{X}_{4,12}$ & & & & & & & & \\
\hline Number 5 roll & & & & $\bar{X}_{5,1}$ & $\bar{X}_{5,2}$ & $\bar{X}_{5,3}$ & $\bar{X}_{5,4}$ & $\bar{X}_{5,5}$ & $\bar{X}_{5,6}$ & $\bar{X}_{5,7}$ & $\bar{X}_{5,8}$ & $\bar{X}_{5,9}$ & $\bar{X}_{5,10}$ & $\bar{X}_{5,11}$ & $\bar{X}_{5,12}$ & & & & & & & \\
\hline Number 6 roll & & & & & $\bar{X}_{6,1}$ & $\bar{X}_{6,2}$ & $\bar{X}_{6,3}$ & $\bar{X}_{6,4}$ & $\bar{X}_{6,5}$ & $\bar{X}_{6,6}$ & $\bar{X}_{6,7}$ & $\bar{X}_{6,8}$ & $\bar{X}_{6,9}$ & $\bar{X}_{6,10}$ & $\bar{X}_{6,11} \mid \overline{3}$ & $\bar{X}_{6,12}$ & & & & & & \\
\hline Number 7 roll & & & & & & $\bar{X}_{7,1}$ & $\bar{X}_{7,2}$ & $\bar{X}_{7,3}$ & $\bar{X}_{7,4}$ & $\bar{X}_{7,5}$ & $\bar{X}_{7,6}$ & $\bar{X}_{7,7}$ & $\bar{X}_{7,8}$ & $\bar{X}_{7,9} \mid \bar{z}$ & $\bar{X}_{7,10} \mid \bar{z}$ & $\bar{X}_{7,11}$ & $\bar{X}_{7,12}$ & & & & & \\
\hline Number 8 roll & & & & & & & $\bar{X}_{8,1}$ & $\bar{X}_{8,2}$ & $\bar{X}_{8,3}$ & $\bar{X}_{8,4}$ & $\bar{X}_{8,5}$ & $\bar{X}_{8,6}$ & $\bar{X}_{8,7}$ & $\bar{X}_{8,8}$ & $\bar{X}_{8,9}$ & $\bar{X}_{8,10}$ & $\bar{X}_{8,11}$ & $\bar{X}_{8,12}$ & & & & \\
\hline Number 9 roll & & & & & & & & $\bar{X}_{9,1}$ & $\bar{X}_{9,2}$ & $\bar{X}_{9,3}$ & $\bar{X}_{9,4}$ & $\bar{X}_{9,5}$ & $\bar{X}_{9,6}$ & $\bar{X}_{9,7}$ & $\bar{X}_{9,8}$ & $\bar{X}_{9,9} \mid \bar{z}$ & $\bar{X}_{9,10}$ & $\bar{X}_{9,11}$ & $\bar{X}_{9,12}$ & & & \\
\hline Number 10 roll & & & & & & & & & $\bar{X}_{10,1}$ & $\bar{X}_{10,2}$ & $\bar{X}_{10,3}$ & $\bar{X}_{10,4}$ & $\bar{X}_{10,5}$ & $\bar{X}_{10,6} \mid \bar{X}$ & $\bar{X}_{10,7} \mid \bar{X}$ & $\bar{X}_{10,8}$ & $\bar{X}_{10,9}$ & $\bar{X}_{10,10}$ & $\bar{X}_{10,11}$ & $\bar{X}_{10,12}$ & & \\
\hline Number 11 roll & & & & & & & & & & $\bar{X}_{11,1}$ & $\bar{X}_{11,2}$ & $\bar{X}_{11,3}$ & $\bar{X}_{11,4}$ & $\bar{X}_{11,5} \mid \bar{X}$ & $\bar{X}_{11,6}$ & $\bar{X}_{11,7}$ & $\bar{X}_{11,8}$ & $\bar{X}_{11,9}$ & $\bar{X}_{11,10}$ & $\bar{X}_{11,11}$ & $\bar{X}_{11,12}$ & \\
\hline Number 12 roll & & & & & & & & & & & $\bar{X}_{12,1}$ & $\bar{X}_{12,2}$ & $\bar{X}_{12,3}$ & $\bar{X}_{12,4} \mid \bar{\gamma}$ & \begin{tabular}{|l|l|}
$\bar{X}_{12,5}$ & $\bar{X}$ \\
\end{tabular} & $\bar{X}_{12,6}$ & $\bar{X}_{12,7}$ & $\bar{X}_{12,8}$ & $\bar{X}_{12,9}$ & $\bar{X}_{12,10}$ & $\bar{X}_{12,11}$ & $\bar{X}_{12,12}$ \\
\hline
\end{tabular}

FIGURE 2: The relation between time and variables of reducing tube.

Adding shell heating temperature $X_{T}$, quality precision variable $X_{\text {transverse }}$ and $X_{\text {longitudinal }}$, one got final input matrix

$$
\begin{aligned}
X= & X_{T}, X_{\text {transverse }}, X_{\text {longitudinal }}, \bar{X}_{1,1}, \bar{X}_{1,2}, \bar{X}_{2,1}, \bar{X}_{1,3} \\
& \bar{X}_{2,2}, \bar{X}_{3,1}, \bar{X}_{1,4}, \bar{X}_{2,3}, \bar{X}_{3,2}, \bar{X}_{4,1}, \bar{X}_{1,5}, \bar{X}_{2,4} \\
& \bar{X}_{3,3}, \bar{X}_{4,2}, \bar{X}_{5,1}, \bar{X}_{1,6}, \bar{X}_{2,5}, \bar{X}_{3,4}, \bar{X}_{4,3}, \bar{X}_{5,2} \\
& \bar{X}_{6,1}, \bar{X}_{1,7}, \bar{X}_{2,6}, \bar{X}_{3,5}, \bar{X}_{4,4}, \bar{X}_{5,3}, \bar{X}_{6,2}, \bar{X}_{7,1}, \\
& \bar{X}_{1,8}, \bar{X}_{2,7}, \bar{X}_{3,6}, \bar{X}_{4,5}, \bar{X}_{5,4}, \bar{X}_{6,3}, \bar{X}_{7,2}, \bar{X}_{8,1} \\
& \bar{X}_{1,9}, \bar{X}_{2,8}, \bar{X}_{3,7}, \bar{X}_{4,6}, \bar{X}_{5,5}, \bar{X}_{6,4}, \bar{X}_{7,3}, \bar{X}_{8,2} \\
& \bar{X}_{9,1}, \bar{X}_{1,10}, \bar{X}_{2,9}, \bar{X}_{3,8}, \bar{X}_{4,7}, \bar{X}_{5,6}, \bar{X}_{6,5}, \bar{X}_{7,4}, \\
& \bar{X}_{8,3}, \bar{X}_{9,2}, \bar{X}_{10,1}, \bar{X}_{1,11}, \bar{X}_{2,10}, \bar{X}_{3,9}, \bar{X}_{4,8}, \bar{X}_{5,7} \\
& \bar{X}_{6,6}, \bar{X}_{7,5}, \bar{X}_{8,4}, \bar{X}_{9,3}, \bar{X}_{10,2}, \bar{X}_{11,1}, \bar{X}_{2,12}, \bar{X}_{3,11}, \\
& \bar{X}_{4,10}, \bar{X}_{5,9}, \bar{X}_{6,8}, \bar{X}_{7,7}, \bar{X}_{8,6}, \bar{X}_{9,5}, \bar{X}_{10,4}, \bar{X}_{11,3} \\
& \bar{X}_{12,2}, \bar{X}_{3,12}, \bar{X}_{4,11}, \bar{X}_{5,10}, \bar{X}_{6,9}, \bar{X}_{7,8}, \bar{X}_{8,7}, \bar{X}_{9,6} \\
& \bar{X}_{10,5}, \bar{X}_{11,4}, \bar{X}_{12,3}, \bar{X}_{4,12}, \bar{X}_{5,11}, \bar{X}_{6,10}, \bar{X}_{7,9}, \bar{X}_{8,8} \\
& \bar{X}_{9,7}, \bar{X}_{10,6}, \bar{X}_{11,5}, \bar{X}_{12,4}, \bar{X}_{5,12}, \bar{X}_{6,11}, \bar{X}_{7,10}, \bar{X}_{8,9} \\
& \bar{X}_{9,8}, \bar{X}_{10,7}, \bar{X}_{11,6}, \bar{X}_{12,5}, \bar{X}_{6,12}, \bar{X}_{7,11}, \bar{X}_{8,10}, \bar{X}_{9,9} \\
& \bar{X}_{10,8}, \bar{X}_{11,7}, \bar{X}_{12,6}, \bar{X}_{7,12}, \bar{X}_{8,11}, \bar{X}_{9,10}, \bar{X}_{10,9}, \bar{X}_{11,8} \\
& \bar{X}_{12,7}, \bar{X}_{8,12}, \bar{X}_{9,11}, \bar{X}_{10,10}, \bar{X}_{11,9}, \bar{X}_{12,8}, \bar{X}_{9,12} \\
&
\end{aligned}
$$

$$
\begin{aligned}
& \bar{X}_{10,11}, \bar{X}_{11,10}, \bar{X}_{12,9}, \bar{X}_{10,12}, \bar{X}_{11,11}, \bar{X}_{12,10}, \bar{X}_{11,12}, \\
& \left.\bar{X}_{12,11}, \bar{X}_{12,12}\right] .
\end{aligned}
$$

Mean values of aforementioned three stage data were arranged from left to right and a data vector $\mathbf{X}(I \times 147)$ consisting of 147 mean values was obtained. The production data of 70 pieces of reducing pipes produced by reducing mill train in Baogang Iron and Steel Group in October 2012 were obtained. Shell diameter was $152.5 \mathrm{~mm}$ and its wall thickness was $6 \mathrm{~mm}$. The reduced diameter was $73.03 \mathrm{~mm}$ and the wall thickness was $5.51 \mathrm{~mm}$. There are total 12 stands. The data were classified into two groups: former 45 pieces were used for establishing quality prediction model, and latter 25 pieces were used for testing the model and checking the estimation precision of reducing pipe quality. The production data of 45 pieces of reducing pipes were spread and a two-dimensional data matrix $X(45,30062)$ was obtained where data gathering cycle was $20 \mathrm{~ms}$, gathering time at bite stage was $2.5 \mathrm{~s}$, gathering time at stable rolling stage was $13 \mathrm{~s}$, and gathering time at steel leaving stage was $1.2 \mathrm{~s}$. Aiming at above data and treating them as shown in Figure 2, one got data matrix $X(45,147)$. Quality prediction model was established using EOS-ELMRPLS algorithm as Figure 3. In the same way, the production data $X$ new $(25,147)$ of 25 pieces of reducing pipes were gathered and quality prediction inspection was performed. In order to compare with the quality prediction model during conventional intermittent process, for the production data of 45 pieces of reducing pipes modeled previously, 39 variables such as motor rotary speeds, currents and torques, heating temperature of shell, and quality precision error of shell for 1st to 12th reducing mills were chosen to act as input variables. Data gathering cycle was $20 \mathrm{~ms}$ and gathering time was $16.7 \mathrm{~s}$. The quality prediction model was established for data matrix 
$X(45,30062)$ using conventional multiway PLS algorithm during simulation modeling.

Similarly, one reorganized the production data of 25 pieces of reducing pipes to form test data matrix $X n(25,30062)$ and perform quality prediction inspection. Figures 4 and 5 show the results of test data prediction for two prediction models.

It is seen in Figures 4 and 5 that within the prediction results of transverse and longitudinal wall thickness in various stages, the prediction precisions of transverse and longitudinal wall thickness based on EOS-ELM-RPLS algorithm were $94.2 \%$ and $93.7 \%$, and the prediction precisions based on conventional multiway PLS algorithm were $90.8 \%$ and $90.3 \%$. This shows that EOS-ELM-RPLS algorithm model possesses higher prediction precision than multiway PLS algorithm model. Based on the quality model using EOS-ELM-RPLS algorithm, using iteration learning control method to modify continuously the variable traces, counteract the influence of model error and unknown undulation; one make the quality of reducing pipe continuously tend to attain ideal indexes.

4.2. Quality Iteration Control of Reducing Pipe Based on Model. After quality model was obtained by calculation, iteration learning control method based on mathematical model was applied to improve the product quality of reducing pipe. Due to the model-plant mismatch and unknown disturbances from batch to batch, the final quality does not always meet the desired product quality in real industry. Batch-tobatch iterative learning control can be used to solve this problem by using the information of previous batch and currant batch to revise the next batch input trajectory. The following model is used to express the input-output relationship:

$$
Y=f(R)
$$

where $Y$ represents the product quality variables and $R=$ $\left[r_{1}, r_{2}, \ldots, r_{N}\right]^{T}$ is a vector of input variables. The nonlinear function $f(\cdot)$ is expressed by the online sequential EOS-ELMRPLS. The first order Taylor series expansion of (28) can be given by

$$
\widehat{y}=f_{0}+\frac{\partial f}{\partial r_{1}} \Delta r_{1}+\frac{\partial f}{\partial r_{2}} \Delta r_{2}+\cdots+\frac{\partial f}{\partial r_{n}} \Delta r_{n} .
$$

For the $k$ th batch, the actual product quality can be written as the sum of the model prediction and its error

$$
y_{k}=\widehat{y}_{k}+\varepsilon_{k}
$$

The prediction of the $(k+1)$ th batch can be approximated and expressed as follows:

$$
\begin{aligned}
\widehat{y}_{k+1} & =\widehat{y}_{k}+\frac{\partial f}{\partial r_{1}}\left(r_{1}^{k+1}-r_{1}^{k}\right)+\cdots+\frac{\partial f}{\partial r_{N}}\left(r_{N}^{k+1}-r_{N}^{k}\right) \\
& =\widehat{y}_{k}+\left[\frac{\partial f}{\partial r_{1}}, \frac{\partial f}{\partial r_{2}}, \ldots, \frac{\partial f}{\partial r_{N}}\right]
\end{aligned}
$$

$$
\begin{aligned}
& \times\left[\left(r_{1}^{k+1}-r_{1}^{k}\right),\left(r_{2}^{k+1}-r_{2}^{k}\right), \ldots,\left(r_{N}^{k+1}-r_{N}^{k}\right)\right]^{T} \\
= & \widehat{y}_{k}+G \Delta R_{k+1},
\end{aligned}
$$

$$
\begin{aligned}
\Delta R_{k+1} & =\left[\left(r_{1}^{k+1}-r_{1}^{k}\right),\left(r_{2}^{k+1}-r_{2}^{k}\right), \ldots,\left(r_{N}^{k+1}-r_{N}^{k}\right)\right]^{T} \\
& =\left[\Delta r_{1}^{k+1} \Delta r_{2}^{k+1}, \ldots, \Delta r_{N}^{k+1}\right]^{T} G \\
& =\frac{\partial y_{i}}{\partial r_{j}}=\left[\frac{\partial f}{\partial r_{1}}, \frac{\partial f}{\partial r_{2}}, \ldots, \frac{\partial f}{\partial r_{N}}\right]=Q \sum_{l=1}^{\widetilde{N}} \frac{\partial y_{i}}{\partial H_{l}} \frac{\partial H_{l}}{\partial r_{j}} P^{T} \\
& =Q \sum_{k=1}^{\widetilde{N}} \beta_{k}^{l, i} H_{k}\left(1-H_{k}\right) \alpha^{j, l} P^{T},
\end{aligned}
$$

where $G$ is the gradient of model output with respect to the input of the EOS-ELM-RPLS. $\alpha_{k}^{j, k}$ is input layer weight from the $j$ th input to the $l$ th hidden node, $\beta^{k, i}$ is the output layer weight from the $l$ th hidden node to the $i$ th output layer node, $H_{k}$ is output of the $l$ th hidden node, and $\widetilde{N}$ is the number of the hidden nodes. The subscript $k$ represents the $k$ th batch.

Let $e$ and $\hat{e}$, respectively, express the actual error and the predicting error corresponding to the desired target. Thus, for the $k$ th batch, the following can be obtained:

$$
\begin{aligned}
& \widehat{e}_{k}=y_{d}-\widehat{y}_{k}, \\
& e_{k}=y_{d}-y_{k}=y_{d}-\widehat{y}_{k}-\varepsilon_{k} .
\end{aligned}
$$

The same as above, the errors for the $(k+1)$ th batch are given by

$$
\begin{aligned}
& \widehat{e}_{k+1}=y_{d}-\widehat{y}_{k+1}, \\
& e_{k+1}=y_{d}-y_{k+1}=y_{d}-\widehat{y}_{k+1}-\varepsilon_{k+1} .
\end{aligned}
$$

Assume that the model prediction errors for the $k$ th batch and the $(k+1)$ th batch are the same. Combining (33) and (34), it gives

$$
e_{k+1}=e_{k}-G^{T} \Delta R_{k+1} \text {. }
$$

The objective of the ILC is to control the input trajectory in order to make the final product quality achieve the desired target. By solving the following optimal quadratic objective function (36), one can get the revised input trajectory for the $(k+1)$ th batch:

$$
\begin{aligned}
\min _{\Delta U_{k+1}} J & =\left\|e_{k+1}\right\|_{Z_{1}}^{2}+\left\|\Delta R_{k+1}\right\|_{Z_{2}}^{2} \\
& =e^{T}{ }_{k+1} Z_{1} e_{k+1}+\Delta R_{k+1}^{T} Z_{2} \Delta R_{k+1},
\end{aligned}
$$

where $Z_{1}$ and $Z_{2}$ are positive definitive weight matrices. Set $\left(\partial J / \partial \Delta R_{k+1}\right)=0$; the partial derivative of the quadratic objective function with respect to the input change $\Delta R_{k+1}$ can be obtained:

$$
\begin{aligned}
\Delta R_{k+1} & =\left(G Z_{1} G^{T}+Z_{2}\right)^{-1} G Z_{1} e_{k}, \\
R_{k+1} & =R_{k}+\Delta R_{k+1} .
\end{aligned}
$$




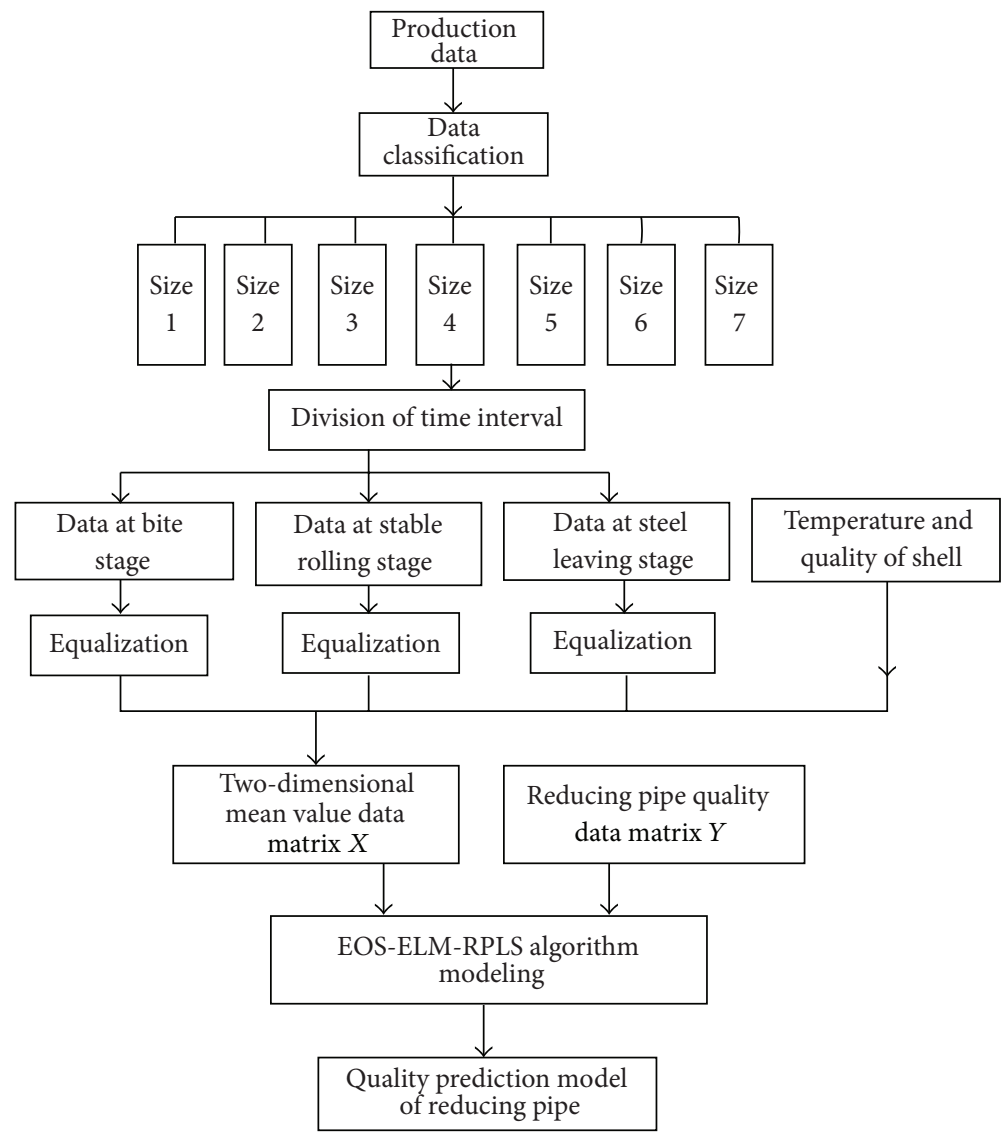

FIgURE 3: Frame chart of reducing tube quality prediction model.

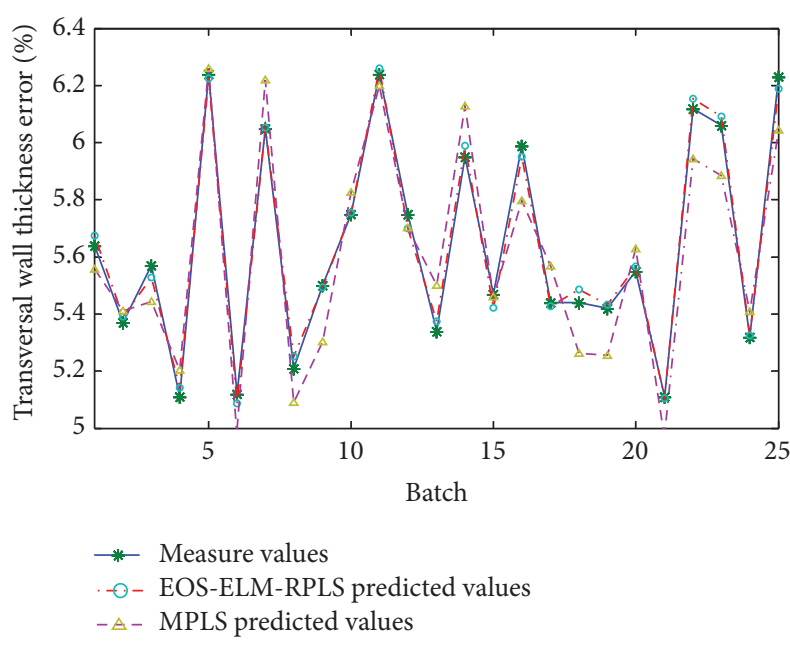

FIGURE 4: Prediction result of transverse wall thickness.

It is to be noted that the change of control trajectory $\Delta R_{k+1}$ is directly updated by the actual tracking error of the process. In many chemical batch processes, however, the actual final quality is impossible to obtain immediately. Thus, the model prediction value could be an alternative. Thus, the tracking performance will depend on the accuracy of the model. The

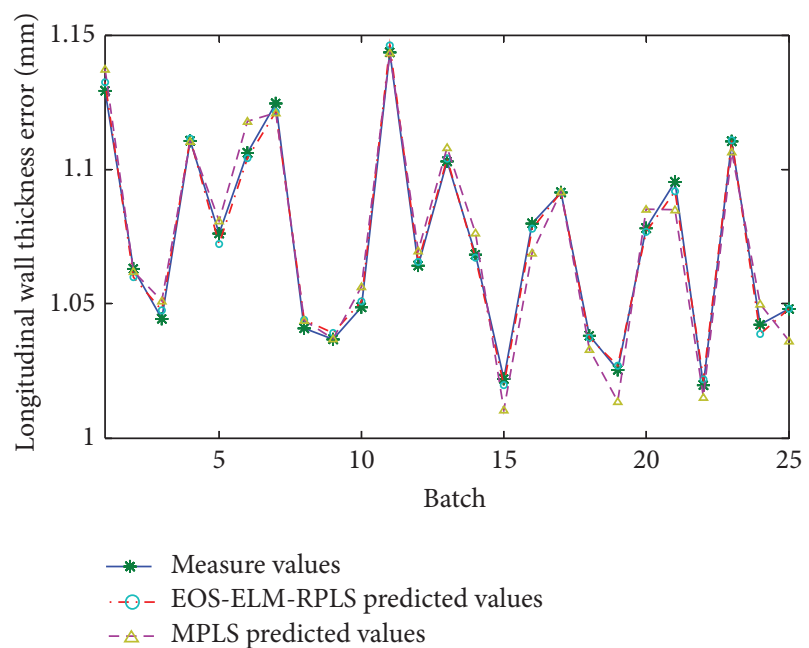

FIgURE 5: Prediction result of longitudinal wall thickness.

convergence of the ILC can directly be derived from the convergence theorems in the literature [24]. It is shown that $e_{k}$ will converge as $k \rightarrow \infty$ if

$$
\|I-G K\|<1,
$$

where $K=\left(G Z_{1} G^{T}+Z_{2}\right)^{-1} G Z_{1}$. 


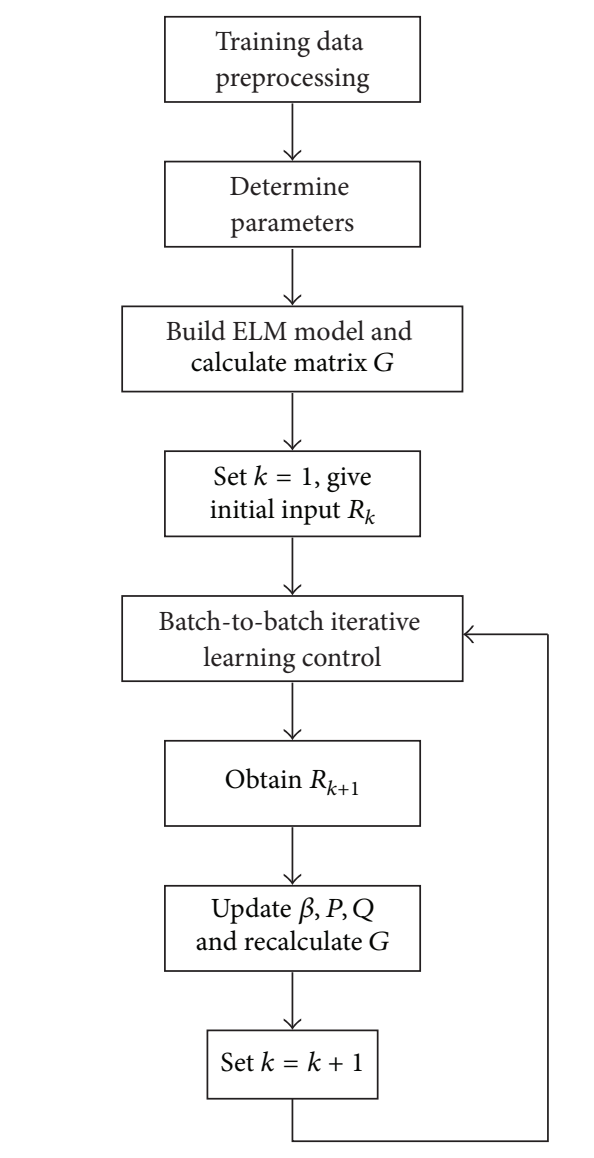

Figure 6: Scheme of ILC based on OSELM-RPLS.

The batch-to-batch iterative learning control scheme of the EOS-ELM-RPLS based method is illustrated in Figure 6. $Q$ and $P$ are the load matrix of PLS decomposition.

Table 3 shows the calculation results of quality iteration learning of reducing pipe. Figures 7 and 8 show the effect of iteration control. The results showed that the quality error of reducing pipe decreased by about $12 \%$ compared with initial error after rolling proceeded to 5 pieces of reducing pipes.

\section{Conclusions}

The production process of reducing pipe continuous rolling has the characteristics of typical multi-time-intervals and dynamic multi-variables. In the meantime, there are many specifications of products, and minor variation of model will occur due to the adjustment of stand for same specification of product; in the meantime, the production of wall reduction and diameter reduction possesses the characteristics of typical multi-time-intervals and dynamic multivariables. The production process was classified into three big time intervals such as bite stage, stable rolling stage, and steel leaving stage influenced by different variables, and according to the sequence that roll touches steel, the production process was further classified into 23 sub-time-intervals; we proposed the reducing production process model based on EOS-ELMRPLS algorithm. This algorithm overcame the shortcomings

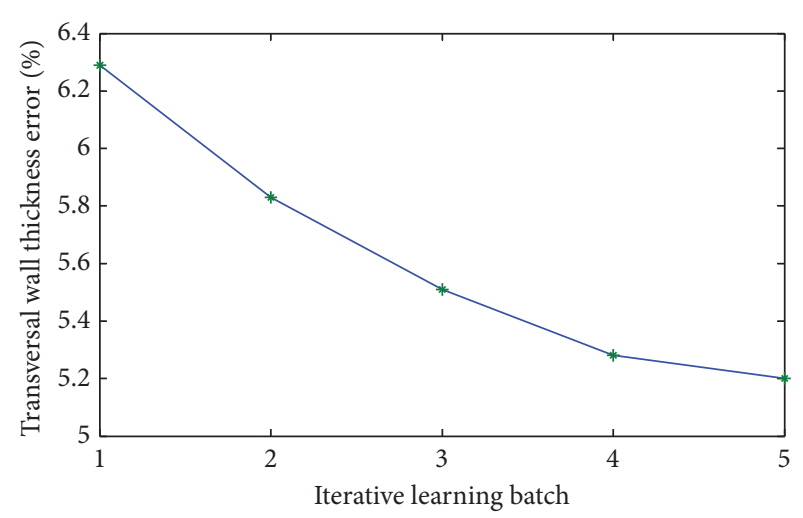

FIGURE 7: Iterative learning control effect of transverse wall thickness.

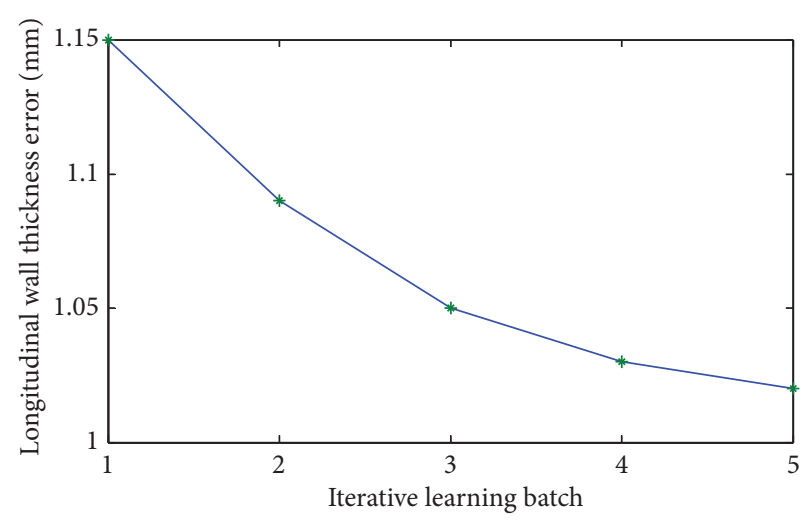

FIGURE 8: Iterative learning control effect of longitudinal wall thickness.

that quality modeling algorithm has complex structure, big calculation load, and bad capability in processing nonlinear problem during conventional intermittent process. Based on the quality prediction model of reducing pipe, we applied iteration learning control technique to the control system of wall thickness deviation and improved the production quality of reducing pipe. Field data simulation and the test results of reducing production in Baogang Iron and Steel Group Steel Pipe Subcompany revealed the validity of this method.

\section{Conflict of Interests}

The authors declare that there is no conflict of interests regarding the publication of this paper.

\section{Acknowledgment}

This research is supported by National Natural Science Foundation of China (Grant no. 61203214), Provincial Science and Technology Department of Education Projects, the General Project (L2013101), National Natural Science Foundation of China (Grant nos. 61203103, 61374146, and 61374147). The study is sponsored by National Natural Science Foundation of China (61203214). 
TABLE 3: Iterative learning calculating result of wall thickness of reducing tube.

\begin{tabular}{|c|c|c|c|c|c|c|}
\hline $\begin{array}{l}\text { Ser. } \\
\text { number }\end{array}$ & Variable name & Initial value & $\begin{array}{c}\text { First } \\
\text { learning value }\end{array}$ & $\begin{array}{c}\text { Second } \\
\text { learning value }\end{array}$ & $\begin{array}{c}\text { Third } \\
\text { learning value }\end{array}$ & $\begin{array}{c}\text { Fourth } \\
\text { learning value }\end{array}$ \\
\hline 1 & $\begin{array}{c}\text { Rotary speed of } \\
\text { Number } 1 \text { reducing mill }\end{array}$ & 1137.52 & 1136.51 & 1134.25 & 1133.15 & 1132.53 \\
\hline 2 & $\begin{array}{l}\text { Rotary speed of } \\
\text { Number } 2 \text { reducing mill }\end{array}$ & 1133.82 & 1132.65 & 1131.58 & 1130.52 & 1130.22 \\
\hline 3 & $\begin{array}{l}\text { Rotary speed of } \\
\text { Number } 3 \text { reducing mill }\end{array}$ & 1288.24 & 1288.93 & 1289.36 & 1290.05 & 1290.22 \\
\hline 4 & $\begin{array}{l}\text { Rotary speed of } \\
\text { Number } 4 \text { reducing mill }\end{array}$ & 1409.32 & 1408.31 & 1407.15 & 1406.53 & 1406.17 \\
\hline 5 & $\begin{array}{l}\text { Rotary speed of } \\
\text { Number } 5 \text { reducing mill }\end{array}$ & 1485.26 & 1483.84 & 1482.37 & 1480.98 & 1480.68 \\
\hline 6 & $\begin{array}{l}\text { Rotary speed of } \\
\text { Number } 6 \text { reducing mill }\end{array}$ & 1458.81 & 1459.84 & 1460.37 & 1460.64 & 1460.87 \\
\hline 7 & $\begin{array}{l}\text { Rotary speed of } \\
\text { Number } 7 \text { reducing mill }\end{array}$ & 1179.95 & 1178.68 & 1177.55 & 1177.09 & 1176.95 \\
\hline 8 & $\begin{array}{l}\text { Rotary speed of } \\
\text { Number } 8 \text { reducing mill }\end{array}$ & 1110.95 & 1109.72 & 1108.66 & 1107.85 & 1107.62 \\
\hline 9 & $\begin{array}{l}\text { Rotary speed of } \\
\text { Number } 9 \text { reducing mill }\end{array}$ & 1290.43 & 1291.42 & 1292.37 & 1293.21 & 1293.38 \\
\hline 10 & $\begin{array}{l}\text { Rotary speed of } \\
\text { Number } 10 \text { reducing mill }\end{array}$ & 1220.67 & 1219.55 & 1218.76 & 1217.84 & 1217.52 \\
\hline 11 & $\begin{array}{l}\text { Rotary speed of } \\
\text { Number } 11 \text { reducing mill }\end{array}$ & 1143.38 & 1141.75 & 1140.53 & 1139.61 & 1138.92 \\
\hline 12 & $\begin{array}{l}\text { Rotary speed of } \\
\text { Number } 12 \text { reducing mill }\end{array}$ & 1103.21 & 1102.33 & 1101.36 & 1100.52 & 1100.22 \\
\hline 13 & $\begin{array}{l}\text { Current of Number } 1 \\
\text { reducing mill }\end{array}$ & 35.46 & 34.75 & 34.24 & 33.97 & 33.91 \\
\hline 14 & $\begin{array}{l}\text { Current of Number } 2 \\
\text { reducing mill }\end{array}$ & 52.48 & 51.62 & 51.28 & 51.07 & 50.98 \\
\hline 15 & $\begin{array}{l}\text { Current of Number } 3 \\
\text { reducing mill }\end{array}$ & 41.54 & 42.37 & 42.97 & 43.31 & 43.42 \\
\hline 16 & $\begin{array}{l}\text { Current of Number } 4 \\
\text { reducing mill }\end{array}$ & 134.52 & 133.75 & 133.24 & 133.94 & 133.87 \\
\hline 17 & $\begin{array}{l}\text { Current of Number } 5 \\
\text { reducing mill }\end{array}$ & 218.21 & 217.47 & 216.84 & 216.37 & 216.28 \\
\hline 18 & $\begin{array}{l}\text { Current of Number } 6 \\
\text { reducing mill }\end{array}$ & 332.46 & 333.23 & 333.86 & 334.32 & 334.44 \\
\hline 19 & $\begin{array}{l}\text { Current of Number } 7 \\
\text { reducing mill }\end{array}$ & 324.46 & 323.71 & 323.14 & 322.71 & 322.62 \\
\hline 20 & $\begin{array}{l}\text { Current of Number } 8 \\
\text { reducing mill }\end{array}$ & 302.35 & 301.43 & 300.85 & 300.18 & 300.02 \\
\hline 21 & $\begin{array}{l}\text { Current of Number } 9 \\
\text { reducing mill }\end{array}$ & 326.87 & 327.95 & 328.56 & 328.83 & 328.92 \\
\hline 22 & $\begin{array}{l}\text { Current of Number } 10 \\
\text { reducing mill }\end{array}$ & 324.37 & 323.65 & 323.15 & 322.97 & 322.88 \\
\hline 23 & $\begin{array}{l}\text { Current of Number } 11 \\
\text { reducing mill }\end{array}$ & 325.84 & 324.77 & 324.24 & 323.95 & 323.86 \\
\hline 24 & $\begin{array}{l}\text { Current of Number } 12 \\
\text { reducing mill }\end{array}$ & 274.94 & 274.04 & 273.65 & 273.13 & 273.04 \\
\hline 25 & $\begin{array}{l}\text { Torque of Number } 1 \\
\text { reducing mill }\end{array}$ & 251.64 & 252.31 & 252.88 & 253.23 & 253.32 \\
\hline 26 & $\begin{array}{l}\text { Torque of Number } 2 \\
\text { reducing mill }\end{array}$ & 320.48 & 321.25 & 321.93 & 322.35 & 322.52 \\
\hline 27 & $\begin{array}{l}\text { Torque of Number } 3 \\
\text { reducing mill }\end{array}$ & 62.44 & 63.12 & 63.34 & 63.52 & 63.57 \\
\hline
\end{tabular}


TABLE 3: Continued.

\begin{tabular}{|c|c|c|c|c|c|c|}
\hline $\begin{array}{l}\text { Ser. } \\
\text { number }\end{array}$ & Variable name & Initial value & $\begin{array}{c}\text { First } \\
\text { learning value }\end{array}$ & $\begin{array}{c}\text { Second } \\
\text { learning value }\end{array}$ & $\begin{array}{c}\text { Third } \\
\text { learning value }\end{array}$ & $\begin{array}{c}\text { Fourth } \\
\text { learning value }\end{array}$ \\
\hline 28 & $\begin{array}{l}\text { Torque of Number } 4 \\
\text { reducing mill }\end{array}$ & 445.85 & 446.87 & 447.66 & 448.02 & 448.21 \\
\hline 29 & $\begin{array}{l}\text { Torque of Number } 5 \\
\text { reducing mill }\end{array}$ & 652.48 & 650.36 & 648.82 & 647.74 & 647.48 \\
\hline 30 & $\begin{array}{l}\text { Torque of Number } 6 \\
\text { reducing mill }\end{array}$ & 1042.68 & 1040.24 & 1039.07 & 1038.21 & 1037.98 \\
\hline 31 & $\begin{array}{l}\text { Torque of Number } 7 \\
\text { reducing mill }\end{array}$ & 1204.15 & 1203.26 & 1202.77 & 1202.35 & 1202.12 \\
\hline 32 & $\begin{array}{l}\text { Torque of Number } 8 \\
\text { reducing mill }\end{array}$ & 1251.42 & 1250.15 & 1249.14 & 1248.48 & 1248.22 \\
\hline 33 & $\begin{array}{l}\text { Torque of Number } 9 \\
\text { reducing mill }\end{array}$ & 1175.25 & 1176.37 & 1177.06 & 1177.84 & 1178.12 \\
\hline 34 & $\begin{array}{l}\text { Torque of Number } 10 \\
\text { reducing mill }\end{array}$ & 1214.85 & 1213.45 & 1212.84 & 1212.25 & 1212.07 \\
\hline 35 & $\begin{array}{l}\text { Torque of Number } 11 \\
\text { reducing mill }\end{array}$ & 1316.47 & 1317.57 & 1318.16 & 1318.54 & 1318.75 \\
\hline 36 & $\begin{array}{l}\text { Torque of Number } 12 \\
\text { reducing mill }\end{array}$ & 1224.46 & 1223.24 & 1222.63 & 1222.22 & 1221.97 \\
\hline 37 & $\begin{array}{c}\text { The temperature } \\
\text { of shell }\end{array}$ & 886 & 892 & 896 & 898 & 901 \\
\hline
\end{tabular}

\section{References}

[1] D. Macrea and C. Cepisca, "Algorithms for speed and stretch control of the main drives of a stretch-reducing tube mill," Revue Roumaine des Sciences Techniques, Serie Electrotechnique et Energetique, vol. 53, no. 1, pp. 99-107, 2008.

[2] L. S. Bayoumi, "Analysis of flow and stresses in a tube stretchreducing hot rolling schedule," International Journal of Mechanical Sciences, vol. 45, no. 3, pp. 553-565, 2003.

[3] F.-P. Zhang, B.-Y. Sun, and J.-M. Wang, "Energy method in stretch reducing process of steel tube," Journal of Iron and Steel Research International, vol. 15, no. 6, pp. 39-43, 2008.

[4] H. Yu, F. Du, and F. Wang, "Finite element model development and application on stretch reducing process of seamless tube," Journal of Mechanical Engineering, vol. 47, no. 22, pp. 74-79, 2011.

[5] H. Yu, F. S. Du, and F. X. Wang, "FE analysis of tube thickness variation in process of 14-stand slight stretch sizing (reducing) mill," Steel Pipe, vol. 35, no. 5, pp. 17-20, 2006 (Chinese).

[6] W. S. Yi, R. Y. Hao, and H. Yu, "Finite-element analysis and experimental research of in-process gage variation of steel tube being slight-stretch reduced," Steel Pipe, vol. 30, no. 1, pp. 15-20, 2001 (Chinese).

[7] Z. Q. Xu and F. S. Du, "A integrated simulation system of stretch reducing of tube and verification," Journal of Yanshan University, vol. 28, no. 1, pp. 36-39, 2004 (Chinese).

[8] F. S. Du, Q. X. Huang, and C. Liu, “The computer predicting in the process of 3-roll reducing of seamless tube," Iron and Steel, vol. 30, no. 7, pp. 28-31, 1995 (Chinese).

[9] Q. Yuan, L. H. Lv, and P. Liu, "Study of the math model of WT variation in 12-stand mini-stretch reducing mill," Steel Pipe, vol. 32, no. 6, pp. 5-8, 2003 (Chinese).

[10] J. H. Shi, C. J. Zhao, and L. P. Bian, "FEA of oval pass of 21-stand stretch reducing mill," Steel Pipe, vol. 41, no. 4, pp. 18-22, 2012 (Chinese).
[11] Y. Shuang, J. Fan, and M. Lai, "Prediction of accuracy of stretch reduction by artificial neural networks," Iron and Steel, vol. 35, no. 2, pp. 28-31, 2000 (Chinese).

[12] B. M. Wang, Hot Rolled Steel Tubes Quality, Metallurgical Industry Press of China, Beijing, China, 1987 (Chinese).

[13] S. Wold, N. Kettaneh-Wold, and B. Skagerberg, "Nonlinear PLS modeling," Chemometrics and Intelligent Laboratory Systems, vol. 7, no. 1-2, pp. 53-65, 1989.

[14] S. J. Qin, "Recursive PLS algorithms for adaptive data modeling," Computers \& Chemical Engineering, vol. 22, no. 4-5, pp. 503-514, 1998.

[15] B. Hu, Z. Zhao, and J. Liang, "Multi-loop nonlinear internal model controller design under nonlinear dynamic PLS framework using ARX-neural network model," Journal of Process Control, vol. 22, no. 1, pp. 207-217, 2012.

[16] G. Feng, Z. Qian, and N. Dai, "Reversible watermarking via extreme learning machine prediction," Neurocomputing, vol. 82, pp. 62-68, 2012.

[17] Y. Yu, T.-M. Choi, and C.-L. Hui, "An intelligent quick prediction algorithm with applications in industrial control and loading problems," IEEE Transactions on Automation Science and Engineering, vol. 9, no. 2, pp. 276-287, 2012.

[18] Y. M. Yang, Y. N. Wang, and X. F. Yuan, "Bidirectional extreme learning machine for regression problem and its learning effectiveness," IEEE Transaction on Neural Network, vol. 23, no. 9, pp. 1498-1505, 2012.

[19] G.-B. Huang, H. Zhou, X. Ding, and R. Zhang, "Extreme learning machine for regression and multiclass classification," IEEE Transactions on Systems, Man, and Cybernetics B: Cybernetics, vol. 42, no. 2, pp. 513-529, 2012.

[20] H.-X. Tian and Z.-Z. Mao, "An ensemble ELM based on modified AdaBoost.RT algorithm for predicting the temperature of molten steel in ladle furnace," IEEE Transactions on Automation Science and Engineering, vol. 7, no. 1, pp. 73-80, 2010. 
[21] S. J. Xie, J. Yang, H. Gong, S. Yoon, and D. S. Park, "Intelligent fingerprint quality analysis using online sequential extreme learning machine," Soft Computing, vol. 16, no. 9, pp. 1555-1568, 2012.

[22] J. Zhao, Z. Wang, and D. S. Park, "Online sequential extreme learning machine with forgetting mechanism," Neurocomputing, vol. 87, pp. 79-89, 2012.

[23] Y. Lan, Y. C. Soh, and G.-B. Huang, "Ensemble of online sequential extreme learning machine," Neurocomputing, vol. 72, no. 13-15, pp. 3391-3395, 2009.

[24] J. H. Lee, K. S. Lee, and W. C. Kim, "Model-based iterative learning control with a quadratic criterion for time-varying linear systems," Automatica, vol. 36, no. 5, pp. 641-657, 2000. 


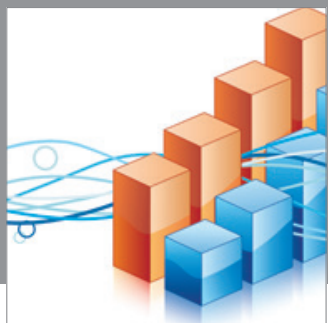

Advances in

Operations Research

mansans

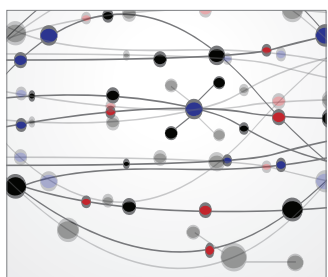

The Scientific World Journal
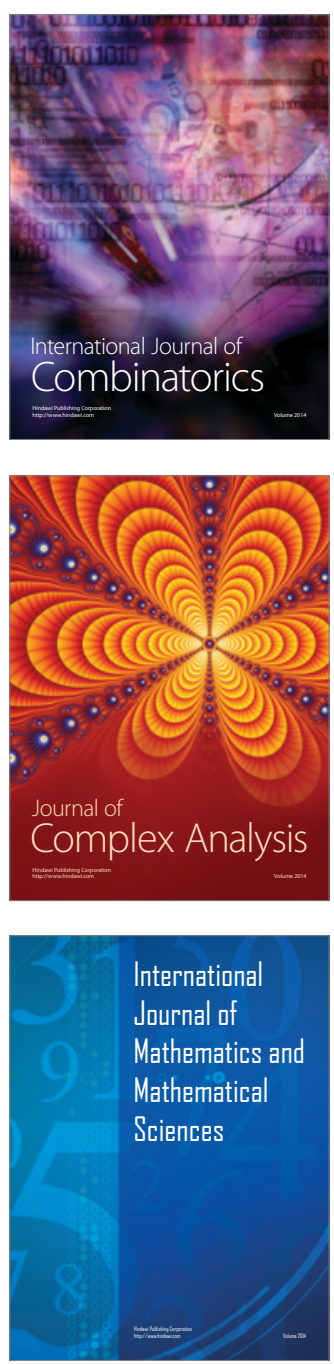
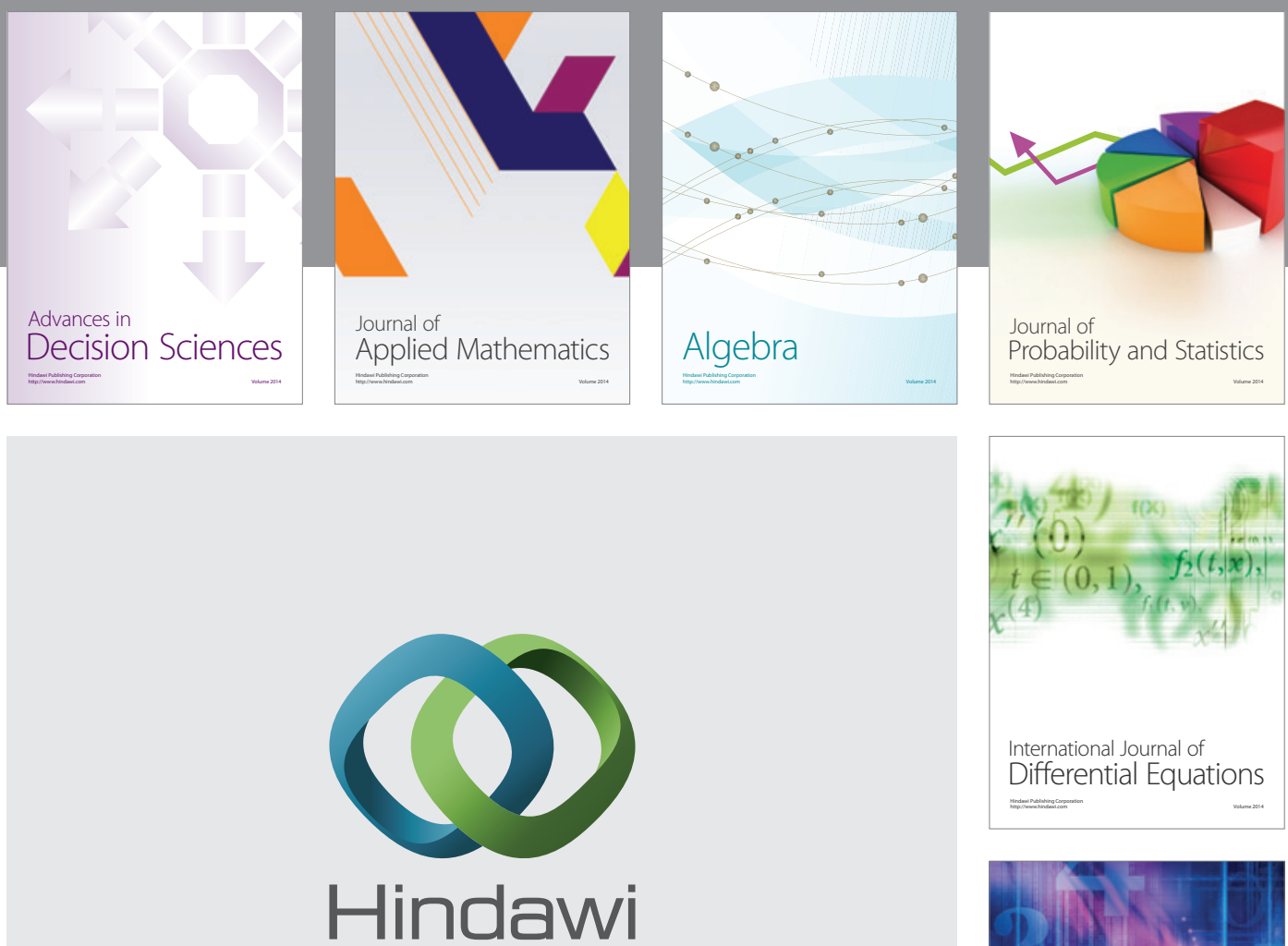

Submit your manuscripts at http://www.hindawi.com
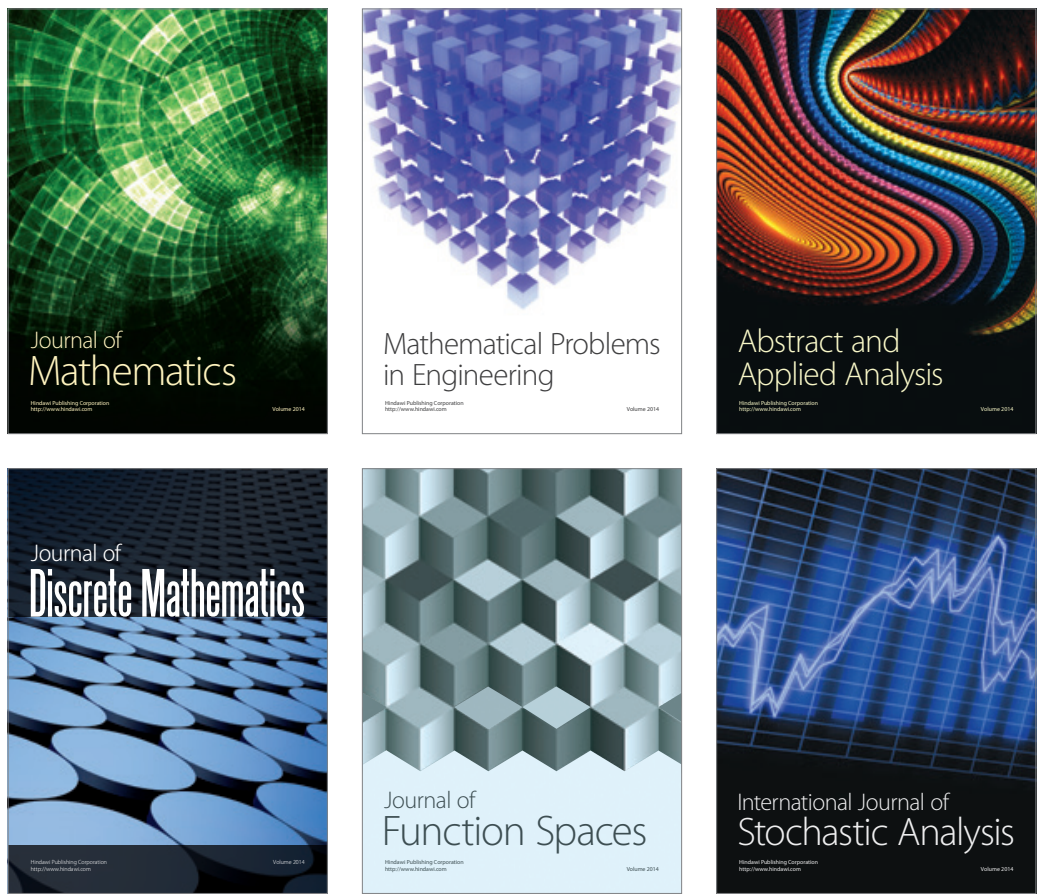

Journal of

Function Spaces

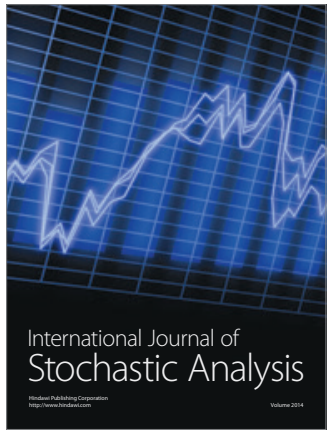

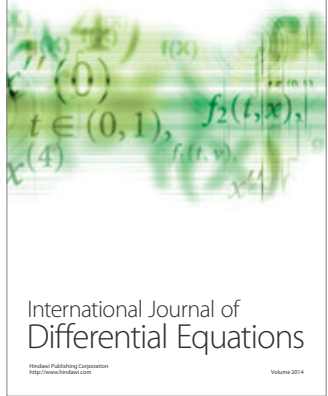
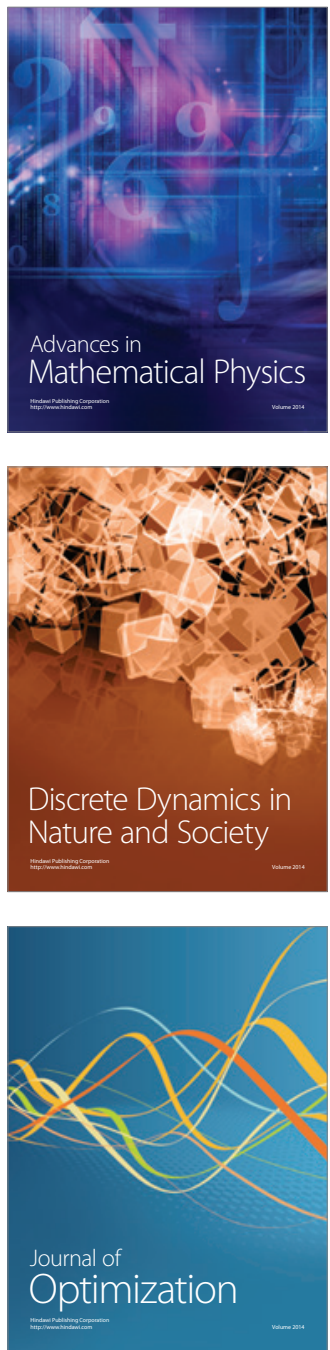